\title{
Analisis Pengaruh Kinerja dan Keistimewaan Features Fotografer Terhadap Kepuasan Konsumen Jasa Fotografi Daus Vto Photowork (DVP)
}

\author{
Revi Vereyanthi Wijaya, Rezi Erdiansyah \\ reviwang90@gmail.com, rezie@fikom.untar.ac.id \\ Fakultas Ilmu Komunikasi Universitas Tarumanagara
}

\begin{abstract}
This research aims to determine the Performance and Features of Daus Vto Photowork (DVP) Photography Service Customers. The research method used is a quantitative method. The sampling technique used was purposive sampling. The population in this research were 100 customers who had used Daus Vto Photowork (DVP) Photography services. The results showed that DVP consumers were found to be satisfied with the results of the performance and features by the photographer. Based on the analysis of statistical data, the indicators in this study are valid and the variables are reliable. Based on the results of the hypothesis test it was concluded that there were influences of performance and features photographer on photography customer satisfaction. This research also provides input and what needs to be considered by Daus Vto Photowork (DVP) to meet customer satisfaction.
\end{abstract}

Keywords : performance, features, photography, photografer, customer satisfaction

\begin{abstract}
Abstrak
Penelitian ini bertujuan untuk mengetahui pengaruh Kinerja dan Keistimewaan Fitur Fotografer terhadap Kepuasan Konsumen Jasa Fotografi Daus Vto Photowork (DVP). Metode penelitian yang digunakan adalah metode kuantitatif. Teknik sampling yang digunakan adalah purposive sampling. Populasi dalam penelitian ini adalah 100 orang komsumen yang pernah menggunakan jasa Fotografi Daus Vto Photowork (DVP). Hasil penelitian menunjukkan bahwa konsumen DVP ditemukan puas dengan hasil kinerja dan keistimewaan fitur yang diberikan fotografer. Berdasarkan analisis data statistik, indikator-indikator pada penelitian ini bersifat valid dan variabelnya bersifat reliabel. Berdasarkan hasil uji hipotesis disimpulkan bahwa terdapat pengaruh kinerja dan keistimewaan fotografer terhadap kepuasan konsumen fotografi. Penelitian ini juga memberi masukkan dan apa saja yang perlu diperhatikan oleh Daus Vto Photowork (DVP) untuk memenuhi kepuasan konsumennya.
\end{abstract}

Kata kunci : kinerja, fitur, fotografi, fotografer, kepuasan konsumen

\section{Pendahuluan}

Dunia fotografi dikalangan usia muda menjadi daya tarik tersendiri dari sekedar hobi hingga dijadikan lapangan pekerjaan yang menhasilkan uang. Di era globalisasi yang semakin berkembang, peluang terbuka bagi semua orang untuk melakukan kegiatan fotografi untuk menghasilkan uang. Semakin banyak orang yang tertarik di bidang photography semakin banyak juga persaingan yang ada. Seorang 
fotografer harus mempertahankan kualitasnya untuk dapat bersaing di era globalisasi seperti sekarang. Beberapa hal yang mempengaruhi kualitas fotografi adalah kinerja dan keistimewaan fotografer. Menurut Porter-Lawler (dalam Mulyadi 2007:336) kinerja ditentukan oleh bagaimana bakat dan kemampuan serta persepsi tentang usaha dan peran dalam organisasi. Sementara menurut Kotler dan Amstrong (2006:273) fitur merupakan suatu ciri-ciri atau keistimewaan yang dimiliki oleh suatu objek atau produk.

Pada dasarnya kepuasan konsumen adalah kunci sukses untuk seorang fotografer agar dapat mencapai keberhasilan, Kotler (2003: 61) mendefinisikan kepuasan sebagai ungkapan perasaan dari seseorang atas hasil produk dengan harapan. Kaitan penelitian dengan public relations adalah dalam salah satu fungsi public relations yaitu menciptakan hubungan harmonis dan menguntungkan kedua belah pihak (dalam kasus ini DVP dan konsumennya) dan mendorong tercapainya saling pengertian antara penjual jasa dan penerima jasa.

Daus Vto Photowork (DVP) berdiri sejak tahun 2015. Bergerak di bidang photography prawedding, wedding, product, documentary dan lain - lain. Penulis tertarik dengan jasa photography ini karena telah banyak dipercaya oleh brand atau pihak ternama seperti Mustika Ratu, Lyra serta Kementrian dalam Negeri dan masih banyak yang lainnya. Dengan ini, penulis ingin mengetahui besarnya pengaruh performance dan feature photografer DVP terhadap kepuasan konsumennya.

Landasan Teori, Performance Photographer: Menurut Porter-Lawler (dalam Mulyadi, 2007:336) kinerja ditentukan oleh bagaimana bakat dan kemampuan serta persepsi tentang usaha dan peran dalam organisasi. Orang yang memiliki bakat dan kemampuan untuk menghasilkan produk atau jasa yang diharapkan. Bakat dan kemampuan tidak cukup bila tidak dimotivasi untuk bekerja. Aktivitas fotografi tentu juga harus memiliki konsep perencanaan yang berkembang menjadi implementasi praksis dengan dukungan peralatan yang mendukung. (Soedjono, 2007:14).

Dalam penelitian ini, indikator untuk mengukur kinerja fotografer, yaitu sebagai berikut:

a. Kualitas dari pencahayaan yang dihasilkan baik.

b. Foto yang dihasilkan tajam dan jelas.

c. Hasil yang memberikan kesan kepada konsumen.

d. Hasil foto mengikuti perkembangan jaman digital.

e. Unggul untuk pemotretan beragam kebutuhan fotografi. (Garvin, 1987 dalam Setiyawati, 2009).

Keistimewaan Features:

Kotler dan Amstrong (2006:273). Keistimewaan fitur merupakan karakteristik yang dimiliki objek dan membedakannya dengan objek lainnya. Produk dapat dinilai oleh konsumen dengan berbagai perbandingan keistimewaaan suatu produk dengan produk pesaing.

Dalam seni fotografi, keistimewaan features seorang fotografer sangat penting untuk menjadi identitas dari seorang fotografer. Keistimewaan features bagi seorang photografer ini meliputi:

a. Pengetahuan untuk memotret beragam kebutuhan fotografi.

b. Inovasi yang unik dan menarik sehingga dapat menarik konsumen.

c. Hasil foto berkesan indah untuk dilihat.

d. Memiliki keistimewaan yang membedakan hasil foto dengan hasil foto fotografer lainnya. (Garvin, 1987 dalam Setiyawati, 2009). 
Revi Vereyanthi Wijaya, Rezi Erdiansyah: Analisis Pengaruh Kinerja dan Keistimewaan Features Fotografer Terhadap Kepuasan Konsumen Jasa Fotografi Daus Vto Photowork (DVP)

\section{Kepuasan Konsumen:}

Menurut Tjiptono (2012:301), Kepuasan konsumen adalah keadaan dimana konsumen merasa kebutuhan dan keinginannya terpenuhi dengan baik. Adapun Kotler dan Keller (2007:177) menyatakan bahwa "Kepuasan adalah reaksi yang ditunjukkan oleh seseorang dengan membandingkan kinerja dan hasil dari suatu produk".

Berikut indikator-indikator untuk mengukur kepuasan konsumen, menurut Yuliarmi dan Riyasa (2007) yaitu:

a. Fasilitas dan pelayanan yang sesuai dengan harapan.

b. Hasil yang memuaskan dibanding dengan produk yang sama.

c. Tidak ada komplain dari konsumen yang dilayangkan.

\section{Metode Penelitian}

Penelitian ini menggunakan pendekatan kuantitatif, menurut Sugiyono (2013 : 36) penelitian kuantitatif dapat diartikan sebagai penelitian yang berlandaskan pada filsafat positivism, digunakan untuk meneliti pada populasi atau sampel tertentu, teknik pengambilan sampel pada umumnya dilakukan secara random, pengumpulan data dilakukan dengan instrumen penelitian, analisis data bersifat kuantitatif atau statistik dengan tujuan untuk menguji hipotesis yang telah ditetapkan. Populasi pada penelitian ini berfokus pada konsumen Daus Vto Photowork (DVP). Sebanyak 115 konsumen populasi dijadikan sampel, setelah diteliti akhirnya diambil sampel sebanyak 100 orang konsumen. Data yang dipergunakan dalam penelitian ini adalah data yang diambil langsung agar dapat dikaji dalam bentuk hasil kuesioner. Selain itu juga dibutuhkan data sekunder berupa studi kepustakaan dan skala pengukuran. Instrumen penelitian yang menggunakan Skala Likert dapat dibuat dalam bentuk checklist ataupun pilihan ganda (Sugiyono, $2013: 169$ ).

Skala Likert sebagai berikut :
a. Sangat Setuju
b. Setuju
c. Ragu-Ragu
d. Tidak Setuju
e. Sangat Tidak Setuju

Teknik analisis data dalam penelitian ini yaitu uji validitas, uji relibilitas dan uji normalitas, sedangkan untuk pengolahan data dalam penelitian ini menggunakan uji T, uji F, uji regresi berganda (multikolinieritas dan autokorelasi), uji koefisien korelasi, dan uji koefisien determinasi. Hipotesis dalam penelitian ini adalah :

$\mathrm{Ho}_{1}$ : Kinerja fotografer tidak berpengaruh terhadap kepuasan konsumen

fotografi. $\mathrm{Ha}_{1}$ : Kinerja fotografer berpengaruh terhadap kepuasan konsumen fotografi.

$\mathrm{Ho}_{2}$ : Keistimewaan atau dimensi fitur fotografer tidak berpengaruh terhadap kepuasan konsumen fotografi.

$\mathrm{Ha}_{2} \quad$ : Keistimewaan atau dimensi fitur fotografer berpengaruh terhadap kepuasan konsumen fotografi.

$\mathrm{Ho}_{3} \quad$ : Kinerja dan keistimewaan atau dimensi fitur fotografer tidak secara bersama-sama berpengaruh terhadap kepuasan konsumen fotografi.

$\mathrm{Ha}_{3}$ : Kinerja dan keistimewaan atau dimensi fitur fotografer secara bersama-sama berpengaruh terhadap kepuasan konsumen fotografi. 


\section{Hasil Temuan dan Diskusi}

\section{Uji Validitas}

Berdasarkan hasil pengolahan SPSS Ver. 16 menunjukkan bahwa hasil uji validitas terhadap 7 butir pernyataan dari variabel performance (X1), 5 butir pernyataan dari variabel features (X2), dan 7 butir pernyataan dari variabel kepuasan konsumen (Y) pada Jasa Photography Daus Vto Photowork (DVP) dinyatakan valid karena angka korelasi diatas 0,2 pada kolom corrected item-total correlation.

\section{Uji Reliabilitas}

Uji reliabilitas merupakan alat uji untuk mengetahui tingkat kestabilan dari suatu alat ukur. Jika lebih besar dari 0,6 maka suatu pengukuran dikatakan reliabel. Hasil pengujian pada variabel performance menunjukkan hasil 0,745 , hasil variabel features sebesar 0,722, hasil variabel kepuasan konsumen sebesar 0,627 dan dinyatakan reliabel.

\section{Uji Normalitas}

Berdasarkan hasil pengolahan SPSS Ver. 16 menunjukkan bahwa nilai Asymp. Sig harus lebih besar dari 0,05 untuk mencapai data yang terdistibusi normal. Variabel performance (X1) 0,053, variabel features (X2) 0,059, dan variabel kepuasan konsumen (Y) 0,057.

\section{Uji Hipotesis}

a. Uji Regresi Linier Berganda (Uji Multikolinieritas dan Uji Autokorelasi)

Uji Multikolinieritas dilakukan untuk mengetahui apakah terjadi korelasi diantara variabel independen. Jika hasil lebih kecil dari 0,8 berarti menunjukkan bahwa model regresipenelitian baik karena tidak terjadi korelasi diantara variabel independen. Berdasarkan hasil penelitian besar korelasi X1 dan X2 adalah 0,511 yang berarti tidak terjadi multikolinieritas.

Uji Autokorelasi dilihat dari tabel Durbin-Watson, Pada penelitian ini hasil perhitungan SPSS nilai Durbin-Watson yaitu 1.451. Nilai tersebut akan dibandingkan dengan tabel Durbin-Watson untuk mendapatkan nilai dU (batas atas) dan dL (batas bawah).

Dengan $\mathrm{n}=100$ (jumlah sampel), $\mathrm{k}=2$ (jumlah variabel independen), dan $\alpha=$ 5\% (nilai tabel signifikansi), tabel Durbin-Watson menunjukan nilai dL adalah 1,633 dan nilai dU adalah 1,715. Kemudian dihitung nilai 4-dU, maka menghasilkan 2,285 (4-1,715)

Hasilnya adalah DW berada di antara nilai dU dan 4-dU $(1,715>1,451<$ 2,285), sehingga tidak terjadi autokorelasi berarti bahwa model regresi penelitian dapat dikatakan baik.

\section{b. Uji T}

Hipotesis 1 : untuk melihat variabel performance (X1) terdapat nilai t sebesar 6,012 dengan sig. sebesar $0,000<0,05$, artinya terdapat pengaruh performance terhadap kepuasan konsumen.

Hipotesis 2 : variabel features (X2) terdapat nilai t sebesar 4,787 dengan sig. sebesar $0,000<0,05$, artinya terdapat pengaruh features terhadap kepuasan konsumen. 


\section{c. Uji F}

Hipotesis 3 : diperoleh dari hasil f sebesar 21,649 dengan nilai sig. sebesar 0,000 $<0,05$, artinya terdapat pengaruh performance dan features photographer terhadap kepuasan konsumen photography.

Dengan melihat hasil uji t hipotesis menunjukkan hasil yang cukup baik, yaitu Kinerja fotografer $\left(\mathrm{X}_{1}\right)$ dan Keistimewaan features fotografer $\left(\mathrm{X}_{2}\right)$ secara individual memiliki pengaruh terhadap Kepuasan Konsumen Fotografi ( $\mathrm{Y}$ ). Berdasarkan hasil uji f hipotesis menunjukkan bahwa variabel kepuasan konsumen (Y) memiliki nilai sig 0,000 $<0,05$ artinya ada variabel $\mathrm{X}$ (kinerja dan keistimewaan) yang memengaruhi kepuasan konsumen (Y). Penelitian ini juga dirujuk berdasarkan penelitian terdahulu.

Dari penelitian ini terdapat 3 variabel, yaitu variabel Kinerja $\left(\mathrm{X}_{1}\right)$ dan variabel Keistimewaan $\left(\mathrm{X}_{2}\right)$ sebagai variabel independent, serta variabel Kepuasan Konsumen (Y) sebagai variabel dependent. Penelitian ini dibuat dengan tujuan untuk mengetahui besarnya pengaruh dari kineja dan keistimewaan fotografer terhadap kepuasan konsumen Daus Vto Photowork (DVP).

Berdasarkan hasil uji validitas sebanyak 19 butir pernyataan pada performance (7), features (5), dan kepuasan konsumen (7) dinyatakan valid. Hasil uji realibilitas pada variabel independen dan dependen dinyatakan reliabel. Hasil dari uji regresi linier berganda (uji multikolinieritas dan uji autokorelasi) menunjukan bahwa model regresi penelitian baik karena tidak terjadi autokorelasi.

Berdasarkan hasil analisis dapat disimpulkan bahwa tidak terdapat perbedaan diantara kedua variabel dependen dalam mempengaruhi variabel independen. Kinerja (performance) berpengaruh terhadap kepuasan konsumen dan keistimewaan features berpengaruh terhadap kepuasan konsumen. Dan secara bersamaan kedua variabel tersebut memiliki pengaruh terhadap kepuasan konsumen.

Maka berdasarkan pembahasan diatas, dapat disimpulkan bahwa Daus Vto Photowork (DVP) adalah salah satu institusi jasa fotografi yang memiliki kinerja dan keistimewaan fotografer yang baik sehingga memberikan kepuasan bagi konsumen yang menggunakan jasa fotografi tersebut khususnya variabel kinerja yang memiliki nilai mean lebih tinggi diantara variabel lainnya yang artinya bahwa variabel kinerja yang paling berpengaruh.

\section{Simpulan}

Sesuai dengan hasil uji statistik, maka dapat dikemukakan bahwa:

1. Berdasarkan hasil uji hipotesis kinerja fotografer $\left(\mathrm{X}_{1}\right)$ terhadap kepuasan konsumen fotografi (Y), terdapat pengaruh kinerja terhadap kepuasan konsumen Daus Vto Photowork (DVP) dengan interval korelasi dan 0,519 koefisien determinasi sebesar $26,9 \%$.

2. Bedasarkan hasil uji hipotesis keistimewaan features fotografer $\left(\mathrm{X}_{2}\right)$ terhadap kepuasan konsumen fotografi (Y), terdapat pengaruh keistimewaan features fotografi terhadap kepuasan konsumen Daus Vto Photowork (DVP) dengan interval korelasi 0,435 dan koefisien determinasi sebesar 19,0\%.

3. Berdasarkan hasil uji hipotesis kinerja fotografer $\left(\mathrm{X}_{1}\right)$ dan keistimewaan features fotografer $\left(\mathrm{X}_{2}\right)$ terhadap kepuasan konsumen fotografi $(\mathrm{Y})$, terdapat pengaruh antara kinerja fotografer dan keistimewaan features fotografer 
terhadap kepuasan konsumen Daus Vto Photowork (DVP) dengan interval korelasi 0,556 dan koefisien determinasi sebesar 30,9\%.

Hasil penelitian menyimpulkan bahwa Kinerja dan Keistimewaan features fotografer berpengaruh positif terhadap kepuasan konsumen fotografi. Pentingnya kepuasan konsumen harus dijaga oleh Daus Vto Photowork (DVP) agar adanya peningkatan yang lebih memuaskan dan inovasi-inovasi unik lainnya agar konsumen merasa puas dengan hasil dari Daus Vto Photowork (DVP) tersebut.

Melihat hasil penelitian dan keterbatasan penelitian, maka disarankan bagi para peneliti berikutnya adalah sebagai berikut:

1. Lebih mendalami lagi variabel Kinerja, Keistimewaan Features dan juga Kepuasan Konsumen serta tentang Fotografi, karena variabel-variabel tersebut memiliki penjelasan yang lebih dalam lagi dan juga menarik untuk diteliti.

2. Adanya penambahan jumlah sampel sehingga hasil penelitian dapat digeneralisasikan dan mendapatkan kesimpulan yang lebih baik, dimana sampel dapat dipilih berdasarkan kriteria tertentu, bukan sensus,

3. Penelitian ini dikembangkan kembali dengan menggunakan metode ganda, yaitu kuantitatif dan kualitatif. Maka, diharapkan akan menghasilkan pembahasan penelitian yang lebih mendalam dan lebih luas mengenai variabel yang diujikan.

4. Saran bagi Daus Vto Photowork (DVP), yaitu meningkatkan kinerja dan keistimewaan features fotografernya untuk menjamin kepuasan konsumen agar konsumen ingin menggunakan jasa Daus Vto Photowork (DVP) kembali.

5. Dimensi kemampuan individu dan tingkat usaha yang dimiliki Daus Vto Photowork (DVP) dapat lebih ditingkatkan karena menjadi nilai jual yang tinggi bagi DVP.

6. Cara kerja yang profesional dari Daus Vto Photowork (DVP) harus diperhatikan karena kurang dari penlaian pada penelitian ini.

\section{Ucapan Terima Kasih}

Puji Syukur kepada Tuhan Yang Maha Esa, karena telah melimpahkan berkat dan rahmat-Nya sehingga saya dapat menyelesaikan jurnal ini dengan baik.

Penyusunan jurnal ini tidak akan terwujud tanpa adanya bantuan dan dukungan dari berbagai pihak. Oleh karena itu saya ingin menyampaikan ucapan terima kasih kepada yang terhormat :

1. Ibu Dr. Riris Loisa, M.Si. selaku Dekan Fakultas Ilmu Komunikasi Universitas Tarumanagara.

2. Bapak Yugih Setyanto S.Sos.M.si. selaku Wakil Dekan Fakultas Ilmu Komunikasi Universitas Tarumanagara.

3. Ibu Sinta Paramita S.I.P.,M.A. Selaku Kepala Program Studi Ilmu Komunikasi Universitas Tarumanagara.

4. Seluruh Dosen Fakultas Ilmu Komunikasi Universitas Tarumanagara yang telah memberi bekal ilmu dan wawasan yang bermanfaat dan berguna.

5. Kepada keluarga yang selalu memberi dorongan, semangat, motivasi, serta selalu mendoakan saya dalam menyelesaikan tugas-tugas baik dari perkuliahan. 
6. Serta kepada sahabat-sahabat saya, teman-teman kuliah, teman seperjuangan, dan juga yang telah ikut terlibat dalam membantu serta memberi movitasi sehingga dapat memberikan yang terbaik.

7. Terimakasih kepada bapak Firdaus Viton yang telah memberikan kesempatan bagi penulis untuk melakukan penelitian ditempatnya.

8. Para Responden yang telah meluangkan waktu untuk mengisi kuisioner.

9. Semua pihak yang telah membantu sehingga terselesaikannya laporan skripsi ini.

Semoga apa yang telah dipelajari dan diberikan mampu saya kembangkan dan gunakan dengan baik tanpa mengecewakan pihak-pihak yang terlibat dalam penelitian saya. Saya juga menyadari bahwa masih banyak kekurangan dalam penyusunan jurnal ini baik dalam teknik penyajian materi maupun pembahasan. Oleh karena itu segala saran maupun kritikan yang bersifat membangun sangat diharapkan untuk dapat menjadi referensi bagi saya dalam penelitian selanjutnya.

\section{Daftar Pustaka}

Kotler, Amstrong. (2006). Principle of Marketing, Elevent Edition, Copy by Pearson Education

Kotler, P. (2003). Marketing Management. 11th Edition, Prentice-Hall, Upper Saddle River.

Lovelock, Christopher\&Wirtz, Jochen. 2007. Service Marketing People, Technologi, Strategy. Sixth Edition. Prentice Hall.

Mulyadi. (2007). Sistem Perencanaan dan Pengendalian Manajemen.Jakarta: Salemba. Empat

Soedjono, $\quad$ Soeprapto. (2007). Pot-Pourri Fotografi. Jakarta:PenerbitUniversitasTrisakti.

Sugiyono. 2013. Metode Penelitian Penelitian Pendidikan Pendekatan Kuantitatif, Kualitatif, dan $R \& D$. Bandung: Alfabeta.

Tjiptono, Fandy. (2012). Service Manajemen Mewujudkan Layanan Prima.Yogyakarta: CV Andi Offset.

Andree Wijaya Suhaji. (2012). Pengaruh Kemampuan dan Motivasi Terhadap Kinerja Karyawan. Sekolah Tinggi Ilmu Ekonomi Widya Manggala, Semarang.

Januar Efendi Panjaitan dan Ai Lili Yuliati. DeReMa Jurnal Manajemen Vol. 11 No.2, September 2016. Pengaruh Kualitas Pelayanan Terhadap Kepuasan Pelanggan Pada JNE Cabang Bandung. Prodi Administrasi Bisnis, Fakultas Komunikasi dan Bisnis Universitas Telkom.

Ni Nyoman Yuliarmi dan Putu Riyasa. (2007). Analisis Faktor-Faktor Yang Mempengaruhi Kepuasan Pelanggan Terhadap Pelayanan Pdam Kota Denpasar. Ejournal Buletin Studi Ekonomi 2007, Universitas Udayana, Bali.

Onny Juwono.Journal The Winners, Vol. 10 No. 2, September 2009: 109-115. Tingkat Kepuasan Pelanggan Dari Kualitas Jasa Layanan. Universitas Budi Luhur.

Saifur Rosyid. (2015). Analisis Pengaruh Kualitas Layanan, Harga, Dan Kualitas Produk Terhadap Kepuasan Konsumen Menggunakan Jasa Fotografi Komersial Roshvisual. Jurusan Manajemen, Fakultas Ekonomi, Universitas Islam Indonesia. 